Die Uebereinstimmung zwischen den einzelnen Werthen der Lange und Breite eines Flecks ist besonders im Hinblick auf die darauf bezügliche Bemerkung in Nr. 2872 als eine gute $\mathrm{zu}$ bezeichnen.

Von den 21 an 16 Beobachtungstagen gemachten Zeichnungen zeigen fünf (April 12, 13, Juni 29, Aug. I) die Syrtis Major und ihre Umgebung, während die April 2I, Mai 29, Juni 2 und 3 gefertigten hauptsächlich das Mare Cimmerium, sowie Thyle I und II getrennt durch Ulyxis Fretum darstellen. Mai 3 schien der Tithonius Lacus mit dem Solis Lacus in directer Verbindung zu stehen, während Juni 9 nichts davon wahrzunehmen war. Mai 3 lag am vorausgehenden Rande ein sehr heller Fleck, dessen Positionswinkel ich um $14^{\mathrm{h}}$ I I ${ }^{\mathrm{m}} 2$ (mittl. Ortszeit) $z \mathrm{u}$ I I $2^{\circ} 55$ bestimmte. Von den besonders auf der nördlichen Halbkugel des Mars so zahlreich auftretenden Canälen zeigen die an den Tagen April 27, 28, Mai 3, 29, Juni 2, 3, 9, 16, 29, sowie Juli 13 gemachten Skizzen mehr oder weniger deutliche Spuren, doch war der Luftzustand niemals günstig genug, um Einzelheiten erkennen $\mathrm{zu}$ lassen, so dass von einem Wahrnehmen etwaiger Verdoppelungen gar keine Rede sein konnte. Die hauptsächlichsten Flecke sind in der beiliegenden Kartenskizze wiedergegeben.

Strassburg im Elsass, 189 i Febr. 15.

\title{
Beobachtungen des Cometen 1891 ... (Barnard-Denning)
} auf der Sternwarte in Kopenhagen von C.F. Pechüle.

\begin{tabular}{|c|c|c|c|c|c|c|c|c|c|c|}
\hline 1891 & M.Z. Kop. & $\Delta \alpha$ & $\Delta d$ & $\mathbf{V}_{\mathbf{g l}}$. & $\alpha$ app. & $\log p .4 \mid$ & $\delta$ app. & $\log p .4$ & Red. ad I. app. & * \\
\hline ril & $\begin{array}{llll}8^{\mathrm{b}} & 56^{\mathrm{m}} & 43^{\mathrm{s}} \\
9 & 11 & 43 \\
8 & 33 & 12 \\
8 & 46 & 20\end{array}$ & 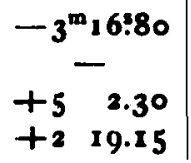 & $\begin{array}{r}-\overline{6} \\
\quad 68: 0 \\
+06.6 \\
+127.4\end{array}$ & $\begin{array}{c}10 \\
3 \\
18.3 \\
24.3\end{array}$ & 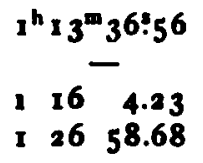 & $\begin{array}{l}9.53^{8} \\
-\overline{960} \\
9.501\end{array}$ & $\begin{array}{rr} & - \\
+39^{\circ} 55^{\circ} 31: 2 \\
+385420.0 \\
+333^{8} 2.2\end{array}$ & $\begin{array}{l}0 . \overline{886} \\
0.865 \\
0.889\end{array}$ & $\begin{array}{r}-2.09- \\
-5-5: 2 \\
-2.05-58 \\
-1.87-6.0\end{array}$ & $\begin{array}{l}2 \\
3\end{array}$ \\
\hline
\end{tabular}

Mittlere Oerter der Vergleichsterne für 1891.0.

Kopenhagen 18,1 April 18.

\begin{tabular}{|c|c|c|c|}
\hline 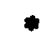 & $a 1891.0$ & $\delta 1891.0$ & Autoritat \\
\hline $\begin{array}{l}\mathbf{I} \\
\mathbf{2} \\
3\end{array}$ & 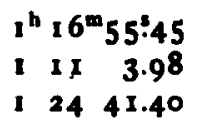 & $\begin{array}{l}+40^{\circ} 2^{\prime} 24^{\prime \prime} 4 \\
+385419.2 \\
+333^{6} 40.8\end{array}$ & $\begin{array}{l}\text { Lund AG. Z. 67, } 83 \\
\text { Yarn. } 651 \text { und Par. } 1615 \\
\text { Leid. AG. Z. } 138,242\end{array}$ \\
\hline
\end{tabular}

\section{Elemente des Cometen 1890 IV.}

Die Elemente sind abgeleitet aus den Beobachtungen

1) Nov. 8 Rom, Dresden; 2) Dec. 8 Strassburg, Bordeaux;

3) Dec. 28 Bordeaux und Dec. 29 Dresden.

Die Darstellung des mittleren Orts wird $(B-R)$ :

$\Delta \lambda \cos \beta=+0 " 3, \Delta \beta=+2.2$.

Strassburg E. 189 I Febr. 18.

$$
\begin{aligned}
& T=1890 \text { Aug. } 7.1928 \text { M. Z. Berlin } \\
& \omega=331^{\circ} 2 I^{\prime} 46 \text {. }^{\prime} 5 \\
& \delta=852239.8 \quad \text { M. Aequ. } 1890.0 \\
& i=\begin{array}{lll}
154 & 19 & 0.7
\end{array} \\
& \log q=0.31 \times 35^{8}
\end{aligned}
$$

C:F. P'echiill: 